\title{
Right ventricular infarction complicated by right to left shunting through an atrial septal defect: successful treatment with an Amplatzer septal occluder
}

\author{
S Bassi, R Amersey, R Andrews
}

Heart 2005;91:e28 (http://www.heartinl.com/cgi/content/full/91/4/e28). doi: 10.1136/hrt.2004.052100

A 68 year old woman presented with right ventricular myocardial infarction complicated by refractory hypoxaemia. She was found to have a significant right to left shunt at the atrial level through a previously undiagnosed ostium secundum atrial septal defect. Percutaneous closure of the atrial septal defect with an Amplatzer septal occluder resulted in prompt improvement in her oxygenation and clinical state. Such closure should be considered for patients with right ventricular infarction and refractory hypoxaemia caused by a right to left interatrial shunt.

$\mathrm{R}$ ight ventricular infarction, first described more than 70 years ago, occurs in nearly half of all acute inferior myocardial infarctions. It is characterised by hypotension, increased jugular venous pressure, and clear lung fields ${ }^{1}$ and is associated with considerable morbidity and mortality, although data regarding long term prognosis are conflicting.

A rare complication of a right ventricular infarction is the development of an acute right to left shunt through a preexisting atrial septal defect (ASD) or persistent foramen ovale (PFO). Right to left shunt should be suspected in patients who develop acute cyanosis and hypoxaemia that is not responsive to administration of high flow oxygen.

We report on a patient with right ventricular infarction who developed right to left shunting through an ASD, which was successfully treated with an Amplatzer septal occluder (AGA Medical Corp, Golden Valley, Minnesota, USA). We also review the literature and consider patient management and alternative treatment strategies.

\section{CASE REPORT}

A 68 year old woman with a history of stroke and atrial fibrillation presented to her local hospital with breathlessness 48 hours after an episode of severe central chest tightness. On arrival in the emergency room, she was centrally and peripherally cyanosed with a respiratory rate of 34 breaths/min and oxygen saturation of $74 \%$. She was in atrial fibrillation with a ventricular rate of 80 beats/min with a blood pressure of $90 / 80 \mathrm{~mm} \mathrm{Hg}$. There were no other relevant physical signs. ECG confirmed atrial fibrillation with ST segment elevation and small Q waves in the inferior leads.

Subsequent serum total creatine kinase estimation of $1806 \mathrm{U} / \mathrm{l}$ (normal range 24-170 U/l) and an increased troponin I concentration of $18.9 \mu \mathrm{g} / \mathrm{l}$ (normal range up to $0.15 \mu \mathrm{g} / \mathrm{l})$ confirmed a recent myocardial infarction. A transthoracic echocardiogram showed a non-dilated left ventricle with inferior hypokinesia and moderately impaired systolic function. The right ventricle was dilated and mildly hypertrophied with impaired contraction of the apex and distal free wall. Doppler studies showed a broad jet of tricuspid regurgitation with a velocity of $2.24 \mathrm{~m} / \mathrm{s}$ giving an estimated pulmonary artery pressure of $20 \mathrm{~mm} \mathrm{Hg}$ plus right atrial pressure. Colour flow mapping showed evidence of an interatrial communication. A chest radiograph was normal and a pulmonary embolism was excluded by a thoracic spiral computed tomogram, which showed normal proximal pulmonary arteries.

The hypoxia was refractory to oxygen treatment (fractional inspired oxygen $\left(\mathrm{FIO}_{2}\right) 0.8$, arterial oxygen tension $5.6 \mathrm{kPa}$, arterial carbon dioxide tension $3.8 \mathrm{kPa}, \mathrm{pH} 7.53$, arterial oxygen saturation $\left(\mathrm{SaO}_{2}\right) 81 \%$ ) and she was transferred to the regional cardiac centre for further management.

On arrival, a contrast transthoracic echocardiogram showed right to left shunting at the atrial level. In view of the symptomatic hypoxia and a deteriorating clinical condition, she was taken urgently to the cardiac catheterisation laboratory.

Cardiac catheterisation was carried out under general anaesthesia with low dose dobutamine for blood pressure support. Coronary arteriography showed an occluded proximal right coronary artery with minor non-obstructive disease of the left system. Right heart catheterisation confirmed the presence of an interatrial communication. The mean right atrial pressure was $9 \mathrm{~mm} \mathrm{Hg}$, mean pulmonary artery pressure was $14 \mathrm{~mm} \mathrm{Hg}$, mean pulmonary capillary wedge pressure was $12 \mathrm{~mm} \mathrm{Hg}$, and mean left atrial pressure was $8 \mathrm{~mm} \mathrm{Hg}$. Oxygen saturations (on $\mathrm{FIO}_{2} 0.8$ ) in the right atrium were $38 \%$, in the main pulmonary artery $32 \%$, and in the left atrium 59\%. Pulmonary vein saturations were $99 \%$ with an aortic saturation of $81 \%$.

Transoesophageal echocardiography showed an ostium secundum ASD and PFO both associated with right to left flow (fig 1). The ASD was crossed with a 7 French multipurpose catheter and an extra support 0.035 inch wire was sited in the left upper lobe pulmonary vein. The ASD was balloon sized under transoesophageal echocardiographic guidance (Equalizer Balloon Occlusion Catheter 8 French $20 \mathrm{~mm}$, Boston Scientific, Natick, Massachusetts, USA) with an estimated stretched ASD diameter of $15 \mathrm{~mm}$. Occlusion of the ASD with the balloon increased right to left shunting through the PFO. A $16 \mathrm{~mm}$ Amplatzer septal occluder was successfully deployed across the defect. Flow across the ASD was arrested with only mild residual right to left flow across the untreated PFO (fig 2).

There was an immediate improvement in arterial saturations $\left(\mathrm{SaO}_{2} 95 \%, \mathrm{FIO}_{2} 0.8\right)$.

After removal of the endotracheal tube, her oxygenation and clinical condition continued to improve $\left(\mathrm{FIO}_{2} 0.4\right.$, arterial oxygen tension $9.6 \mathrm{kPa}$, arterial carbon dioxide tension $\left.5.3 \mathrm{kPa}, \mathrm{pH} 7.39, \mathrm{SaO}_{2} 94 \%\right)$.

Abbreviations: ASD, atrial septal defect; $\mathrm{FlO}_{2}$, fractional inspired oxygen; PFO, persistent foramen ovale; $\mathrm{SaO}_{2}$, arterial oxygen saturation 


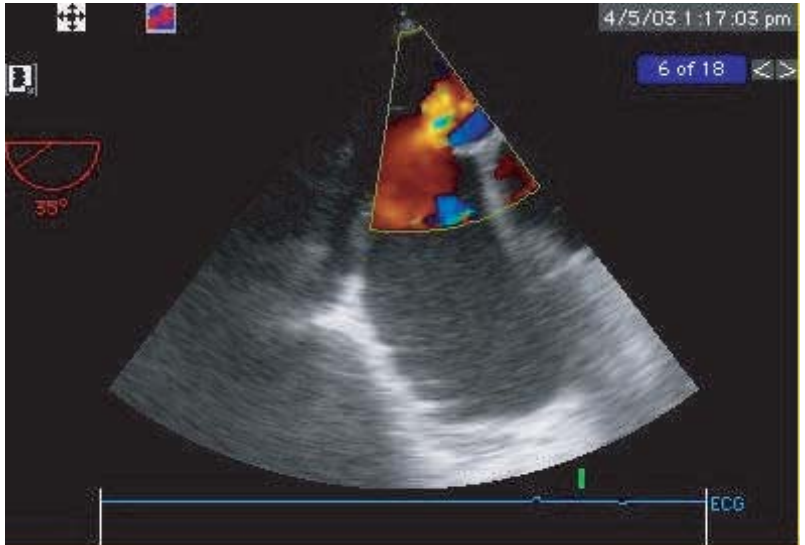

Figure 1 Transoesophageal echocardiogram with colour Doppler showing right to left shunting through an atrial septal defect.

Later the same evening her $\mathrm{SaO}_{2}$ was $91-95 \%$ on air. She was discharged after three days without any sequelae and she remains well.

\section{DISCUSSION}

Right ventricular infarction typically occurs when there is an occlusion of the right coronary artery proximal to the acute marginal branches or of the left circumflex artery in patients with a dominant left coronary system. Less commonly, occlusion of the left anterior descending artery can result in infarction of the anterior right ventricle. ${ }^{2}$

Right ventricular infarction causes reduced right ventricular myocardial compliance with increased right ventricular end diastolic and right atrial pressures. In patients with an interatrial septal defect, a right to left shunt may develop when the right atrial pressure exceeds the left atrial pressure.

The development of cyanosis and refractory hypoxaemia in patients with a recent right ventricular infarction should alert the physician to the possibility of intracardiac shunting at the atrial level.

Treatment strategies for these patients have focused on measures to support the impaired right ventricle. These have included early reperfusion with a fibrinolytic ${ }^{3}$ or primary angioplasty ${ }^{4}$; volume loading to maintain adequate right ventricular preload ${ }^{5}$; positive inotropic support with drugs such as dobutamine ${ }^{6}$ and afterload reducing agents such as sodium nitroprusside or an intra-aortic balloon pump when right ventricular infarction is accompanied by left ventricular failure $^{7}$; direct current cardioversion for atrial fibrillation; and temporary cardiac pacing to maintain atrioventricular synchrony in patients with heart block. ${ }^{8}$ The closure of interatrial defects, either percutaneously or surgically, is usually considered unnecessary and as right ventricular function improves, right to left shunting decreases.

Other treatments that have been successfully used to reduce the right to left shunting in this clinical setting have included temporary balloon catheter occlusion of the interatrial septal defect, ${ }^{9}$ infusion of an ultrashort acting $\beta$ blocker, ${ }^{10}$ inhaled nitric oxide, ${ }^{11}$ intravenous milrinone infusion, ${ }^{12}$ and treatment with oral $\alpha$ l agonist with midodrine. ${ }^{13}$

The measures described above provide only temporary resolution of the right to left shunt pending improvements in right ventricular function. More definitive treatments include percutaneous ${ }^{14}$ or surgical closure of the interatrial shunts.

Percutaneous closure is less invasive and avoids the risks of cardiac surgery in patients with recent myocardial infarction. Our patient was severely hypoxic but after successful acute
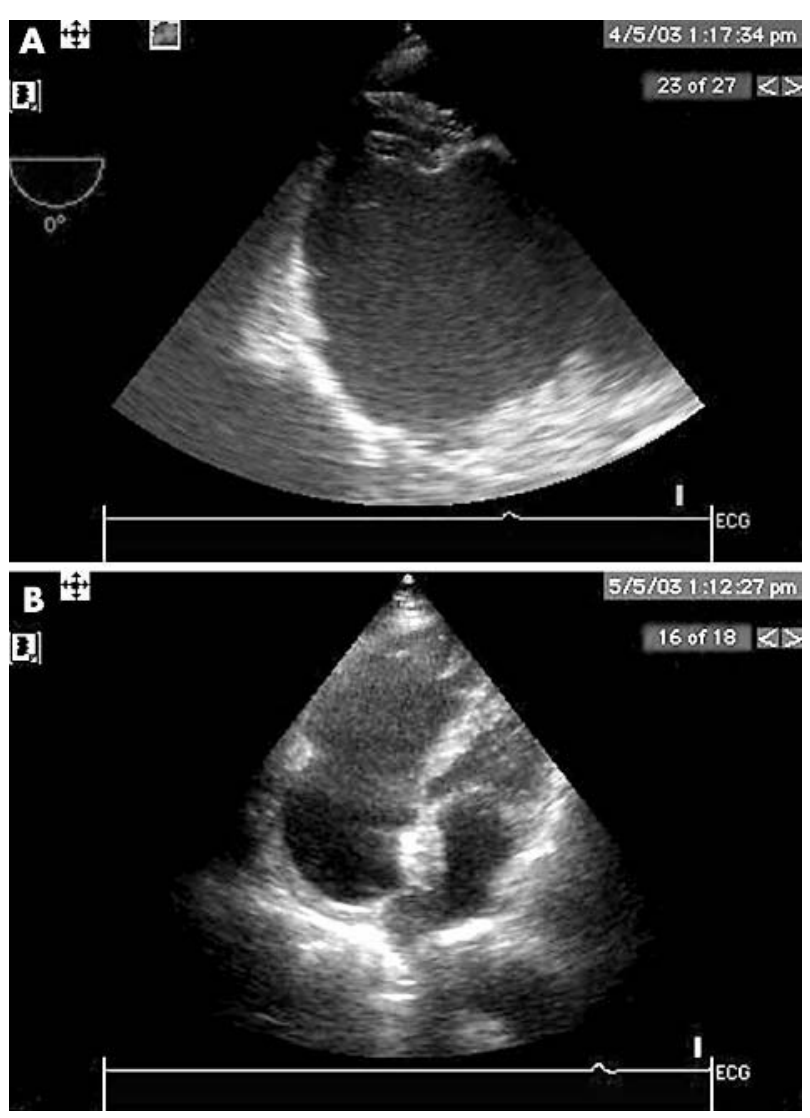

Figure 2 (A) Transoesophageal echocardiogram after deployment of the Amplatzer septal occluder. (B) Transthoracic echocardiogram one day after the procedure.

percutaneous closure of the ostium secundum ASD her clinical state improved immediately.

Percutaneous closure should be considered for patients with right ventricular infarction and refractory hypoxaemia due to right to left interatrial shunts.

\section{ACKNOWLEDGEMENTS}

We thank Dr Robert Henderson, Cardiology Department, Nottingham City Hospital, for his advice and practical expertise with this case.

\section{Authors' affiliations}

S Bassi, R Andrews, Department of Cardiology, Lincoln County Hospital, Lincoln, UK

R Amersey, Department of Cardiology, Nottingham City Hospital, Nottingham, UK

Competing interests: none

Correspondence to: Dr S Bassi, Department of Cardiology, Lincoln County Hospital, Greetwell Road, Lincoln LN2 5QY, UK; bassis@ doctors.org.uk

Accepted 1 November 2004

\section{REFERENCES}

1 Cohn JN, Guiha NH, Broder MI, et al. Right ventricular infarction: clinical and haemodynamic features. Am J Cardiol 1974;33:209-14.

2 Anderson HR, Falk E, Nielsen D. Right ventricular infarction: frequency, size and topography in coronary heart disease: a prospective study comprising 107 consecutive autopsies from a coronary care unit. J Am Coll Cardiol 1987; 10:1223-32.

3 Berger PB, Ruocco NA Jr, Ryan TJ, et al. Frequency and significance of right ventricular dysfunction during inferior wall left ventricular myocardial infarction treated with thrombolytic therapy (results from the thrombolysis in myocardial infarction [TIMI] II trial). Am J Cardiol 1993;71:1148-52. 
4 Moreyra AE, Suh C, Porway MN, et al. Rapid hemodynamic improvement in right ventricular infarction after coronary angioplasty. Chest 1988;94:197-9.

5 Goldstein JA, Vlahakes GJ, Verrier ED, et al. Volume loading improves low cardiac output in experimental right ventricular infarction. J Am Coll Cardio 1983;2:270-8.

6 Dell'Italia L, StarlingMR, Blumhardt R, et al. Comparative effects of volume loading, dobutamine and nitroprusside in patients with predominant right ventricular infarction. Circulation 1985;72:1327-35.

7 Fantidis $\mathbf{P}$, Castejon R, Fernandez Ruiz A, et al. Does a critical hemodynamic situation develop from right ventriculotomy and free wall infarct or from small changes in dysfunctional right ventricle afterload? J Cardiovasc Surg (Torino) 992; $33: 229-34$

8 Love JC, Haffajee Cl, Gore JM, et al. Reversibility of hypotension and shock by atrial or atrioventricular sequential pacing in patients with right ventricular infarction. Am Heart J 1984;108:5-13.

9 Matsuo R, Nakamura T, Matsui $\mathrm{H}$, et al. Treatment of refractory hypoxaemia due to right-to-left shunt complicating right ventricular infarction: successful short term percutaneous catheter closure of the patent foramen ovale. J Cardiol 1995;26:243-8.

10 Broderick TM, Dillon JC. Therapeutic balloon occlusion and pharmacologic therapy of a right-to-left atrial shunt by right ventricular infarction. Am Heart $J$ 1989;118:1044-7.

11 Fessler MB, Lepore JJ, Thompson BT, et al. Right-to-left shunting through a patent foramen ovale in right ventricular infarction: improvement of hypoxaemia and haemodynamics with inhaled nitric oxide. J Clin Anaesth 2003;15:371-4.

12 Park SJ, Gundry SR. Severe right to left shunting through a patent foramen ovale secondary to right ventricular infarction: reversal by milrinone infusion. Chest 1999;116:399S.

13 Chidambaram M, Mink S, Sharma S. Atrial septal aneurysm with right-to-left inter-atrial shunting. Tex Heart Inst J 2003;30:68-70.

14 Laham RL, Ho KKL, Douglas PS, et al. Right ventricular infarction complicated by acute right-to-left shunting. Am J Cardiol 1994;74:824-6. 